\title{
Recovery and economy; salary and allowances: a 10-year follow-up of income for persons diagnosed with first-time psychosis
}

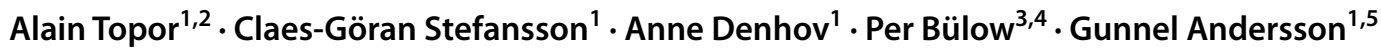

Received: 4 August 2018 / Accepted: 7 January 2019 / Published online: 10 January 2019

(c) The Author(s) 2019

\begin{abstract}
Purpose Persons with severe mental health problems (SMHP) point out financial strain as one of their main problems. Deinstitutionalisation in welfare countries has aimed at normalisation of their living conditions. The aim of the study was to follow the changes in income and source of income during a 10-year period for persons with a first-time psychosis diagnosis (FTPD).

Methods Data were gathered from different registers. Data from persons with FTPD were compared to data on the general population. Two groups with different recovery paths were also compared: one group without contact with the mental health services during the last five consecutive years of the 10-year follow-up, and the other with contact with both 24/7 and community-based services during the same period.

Results SMHP led to poverty, even if the financial effects of SMHP were attenuated by welfare interventions. Even a recovery path associated with work did not resolve the inequalities generated by SMHP.

Conclusions Attention should be paid to the risks of confusing the effects of poverty with symptoms of SMHP and thus pathologizing poverty and its impact on human beings. Adequate interventions should consider to improve the financial situation of persons with SMHP.
\end{abstract}

Keywords Psychosis $\cdot$ Poverty $\cdot$ Financial strain $\cdot$ Long-term follow-up $\cdot$ Recovery

\section{Introduction}

The de-hospitalisation process in most Western countries was partly motivated by the miserable living conditions that the patients were subjected to in the "total institutions" [1]. A core concept for the subsequent changes in the organisation of mental health care services was "normalisation". In

\section{Alain Topor}

alain.topor@socarb.su.se

1 Department of Social Work, Stockholm University, 10691 Stockholm, Sweden

2 Department of Mental Health. Grimstad, University of Agder, Kristiansand, Norway

3 Department of Psychiatry, Ryhov County Hospital, Jönköping, Sweden

4 Department of Behavioural Science and Social Work, School of Health and Welfare, Jönköping University, Jönköping, Sweden

5 Research and Development Unit, FoU Södertörn, Doktorsvägen 2, 14730 Tullinge, Sweden the Scandinavian countries, with their welfare state tradition, normalisation was conceived as the normalisation of the patients' living conditions [2]. A place of one's own, access to opportunities to work and recreational activities, and the financial conditions necessary to use the different possibilities of a life in the community were some of these conditions.

In many countries, the consequences of the downsizing of in-patient care institutions have been mostly described in terms of trans-institutionalisation from mental hospitals to prisons and boarding houses [3-5] and abandonment [6, 7]. The great majority of persons with severe mental health problems (SMHP) remained outside the labour market, and their economic status and living conditions sometimes worsened even if they managed to work [8].

However, it has been difficult to conduct individualbased follow-up studies over time. Harding [9], therefore, made a distinction between follow-up studies and longterm follow-up studies. Long-term studies show important drop-out problems [10] that lead either to short follow-up periods or difficulties drawing conclusions $[11,12]$. It is 
also impossible to follow individuals in the different fields' registers of importance (i.e., mental health and social intervention, mortality, prisons, income, and source of income), except in some Scandinavian countries, where every inhabitant is given a personal number that is used in all his/her contacts with different authorities.

\section{De-hospitalisation in Sweden}

In Sweden, the economic situation of persons leaving mental hospitals for a life in the community was one of the main concerns associated with the "Psychiatry reform" [13] which was carried out in the second half of the 1990s. The main intention of the reform was to give persons with SMHP support for better social living. Therefore, the responsibility for this was legally assigned to the social services to arrange in cooperation with the psychiatric organisation. The parliamentary commission working on the reform studied in particular the financial situation of persons with SMHP in comparison to both other disabled groups and the general population, and also its consequences for these persons' daily living. Persons with SMHP had less disposable income than both other groups. Consequently, they had more difficulty managing everyday expenses; they lived more by themselves, and had fewer friends and fewer holidays [14].

During the years following the reform, the National Board of Health and Welfare (NBHW) (Socialstyrelsen) produced a range of reports, where the situation for persons with SMHP was followed up $[15,16]$. In summary, the persons remained unemployed to a greater extent than other disabled groups. They had less money at their disposal and they were often dependent on social security support. More often than other groups, they showed long-term lasting poverty and dependence on public support. Because of their financial strain, they did not seek help for their health and, as the NBHW stated, "their possibility to have meaningful recreation should be quite limited" [17].

Ten years after the reform, a study focused on their financial situation and its development was carried out [17]. The results showed that for persons with SMHP, their income had stood still over the years. As the disposable income for the general population had increased during the same period, the conclusion was that in reality, the financial situation for the target group had worsened during the years after the reform. Still, the NBHW gave the reminder that: "The aim of the disability policy is to identify and remove hindrances to complete participation in the society and to create equality regarding living conditions for people with disabilities" [17, p 50].

One of the starting points of this article is to study how policy and practice relate to each other, in this specific case focusing on the financial situation of people with SMHP.

\section{Financial strain}

Relative poverty is not solely a question of equality and citizenship. The relationship between poverty and mental health problems is well established [18], but the direction of the causal relationship between the two is still discussed [19]. A persons' financial situation plays an important role in his/her possibility to participate in a social life, to have reciprocal relationships, and to be part of the community [20-22]. Financial strain might also influence the probability of recovery [23-25].

Previous descriptions of the economic development of persons with SMHP have not included the different treatment measures involved or outcomes for different subgroups in relation with their state of recovery. Instead, most approaches treat persons with SMHP as a homogeneous group. For the last few decades, we lack knowledge about changes in the economic situation for persons with SMHP.

\section{Aim}

The aim of this article was to study changes in the economic situation and sources of income for persons with a first-time psychosis diagnosis (FTPD), during a 10-year period following their diagnosis. We also wanted to find out whether and how different recovery paths affected their incomes.

\section{Method}

Data were extracted from a prospective 10-year naturalistic follow-up study of 1480 persons diagnosed with psychosis in Psychiatry South Stockholm's catchment area (282 000 inhabitants, of which 232000 were 18 years and older). The selection criteria were a psychosis diagnosis that complied with DSM-III-IV or ICD 10 and the person had been in contact with these psychiatric services during the year 2004. The study combined register data for the whole population, and interviews with a strategic sample of the participants [26]. The study population could be considered as a total population from the catchment area, as privately financed psychiatric services directed towards persons with a psychosis diagnosis are non-existent in Sweden.

For the purpose of this article, we selected a subsample constituted of all persons who had received a psychosis diagnosis for the first time during the period 2000-2004. This subsample was followed up for 10 years and consisted of 447 persons (Table 1). Fifty-one persons (11.4\%) died during the follow-up period. Ten persons could not be traced in the register, probably because, as newcomers to Sweden, they had not yet received their personal number, 
Table 1 Total and study populations and the different sub-groups

\begin{tabular}{lrcc}
\hline Total population & $\begin{array}{c}\text { Men } \\
244\end{array}$ & $\begin{array}{l}\text { Women } \\
203\end{array}$ & $\begin{array}{l}\text { Total } \\
447\end{array}$ \\
\hline Lapses in registers & 5 & 5 & 10 \\
Deceased & 31 & 20 & 51 \\
Retired persons & 8 & 14 & 22 \\
The study population & 200 & 164 & 364 \\
Sub-groups & & & \\
Institutional recovery & 27 & 26 & 53 \\
Ongoing institutional & 87 & 72 & 159 \\
\hline
\end{tabular}

which allows persons to be traced in the different registers. These groups were excluded from the study, as were 22 retired persons. Consequently, the follow-up group consisted of 364 persons of working age (18-64 years).

In a previous article, we analysed different recovery paths in the study population [27]. In the present article, we will follow two sub-groups with different institutional recovery paths. The first group consisted of 53 persons without any contact with psychiatric or social institutional (in-patient or 24/7 housing accommodation) and community-based care (medical, psychotherapeutic or home support) for the last five consecutive years of the follow-up, and could be considered as an institutional recovery group. The second group consisted of the 159 persons who received psychiatric and/or social institutional-based and community-based care during the last five consecutive years of the follow-up. However, as they had spent most of these years living in the community, they were described as a group having ongoing experiences of institutionalisation.

To investigate whether differences in outcome between these groups were dependent on background data, a logistic regression analysis, both in a crude ODDS -model (Model 0 ) and in a fully adjusted model (Model 1), was carried out (Table 2).

Divorced persons, persons without children at home and those for whom there were 6 years or more between the first psychiatric contact and having the first psychosis diagnosis had an increased risk of belonging to the group with ongoing experiences of institutionalisation according to the crude ODDS (Model 0). However, no differences were observed when a fully adjusted model was applied (Model 1).

The article is based on register data about income and sources of income. We also used register data about interventions from psychiatric and social services, and in-patient and community-based interventions to create both groups.

The economic incomes included in the follow-up were salary from work on the labour market and four kinds of allowances: financial support from social services, sickness benefit, disability pension, and unemployment benefit.
Table 2 Bivariate odds ratios (OR:s) with 95\% confidence intervals for persons with experiences of ongoing institutional contacts $(N=159)$ compared to persons in the institutional recovery group $(N=53)$ the last 5 years of the 10-year follow-up period (Model 0) and mutually adjusted odds ratios (Model 1)

\begin{tabular}{|c|c|c|c|c|}
\hline & \multicolumn{2}{|c|}{ Model 0} & \multicolumn{2}{|c|}{ Model 1} \\
\hline & OR & $95 \%$ CI & OR & $95 \%$ CI \\
\hline \multicolumn{5}{|l|}{ Gender } \\
\hline Women & 1 & & 1 & \\
\hline Men & 1.2 & $0.6-2.2$ & 1.1 & $0.5-2.1$ \\
\hline \multicolumn{5}{|l|}{ Age group (years) } \\
\hline $18-30$ & 1 & & 1 & \\
\hline $31-50$ & 1.5 & $0.8-2.9$ & 1.5 & $0.7-3.3$ \\
\hline $51-64$ & 2.1 & $0.8-5.8$ & 1.5 & $0.4-4.9$ \\
\hline \multicolumn{5}{|l|}{ Marital status } \\
\hline Single & 1 & & 1 & \\
\hline Married & 1.7 & $0.7-12.4$ & 1.9 & $0.7-5.8$ \\
\hline Divorced & 3.6 & $1.1-12.4^{*}$ & 2.9 & $0.8-11.1$ \\
\hline \multicolumn{5}{|c|}{ Children $(<18$ years) at home } \\
\hline Yes & 1 & & 1 & \\
\hline No & 2.2 & $1.1-4.3^{*}$ & 1.6 & \\
\hline \multicolumn{5}{|l|}{ Swedish born } \\
\hline Yes & 1 & & 1 & \\
\hline No & 1.1 & $0.5-2.5$ & 1.8 & $0.6-5.2$ \\
\hline \multicolumn{5}{|l|}{ Education } \\
\hline Post-upper secondary & 1 & & 1 & \\
\hline Upper secondary & 1.7 & $0.8-3.5$ & 1.8 & $0.9-3.9$ \\
\hline Pre-upper secondary & 2.6 & $1-6.7$ & 2.5 & $0.9-7.0$ \\
\hline
\end{tabular}

Number of years between first psychiatric contact and first psychosis diagnosis

$\begin{array}{lllll}0^{\mathrm{a}} & 1 & & 1 & \\ 1-5 & 1.3 & 0.6-2.8 & 1.2 & 0.5-2.9 \\ 6- & 3.4 & 1.3-8.7^{*} & 2.8 & 1.0-7.8\end{array}$

${ }^{a}$ The same year as the psychosis diagnosis was set (2000-2004)

*Statistically significant from the reference group

All economic outcome data are presented in fixed monetary value based on values for 2013 and gross amount.

\section{Findings}

We will first look at data comparing the persons with a FTPD and the general population in Stockholm. Thereafter, we will focus our presentation on findings regarding differences between the institutional recovery group and the recovery with institutionalisation group.

\section{Income for persons with first-time psychosis and for the general population}

Comparing the development of total income for all persons with a first-time psychosis diagnosis with the general 


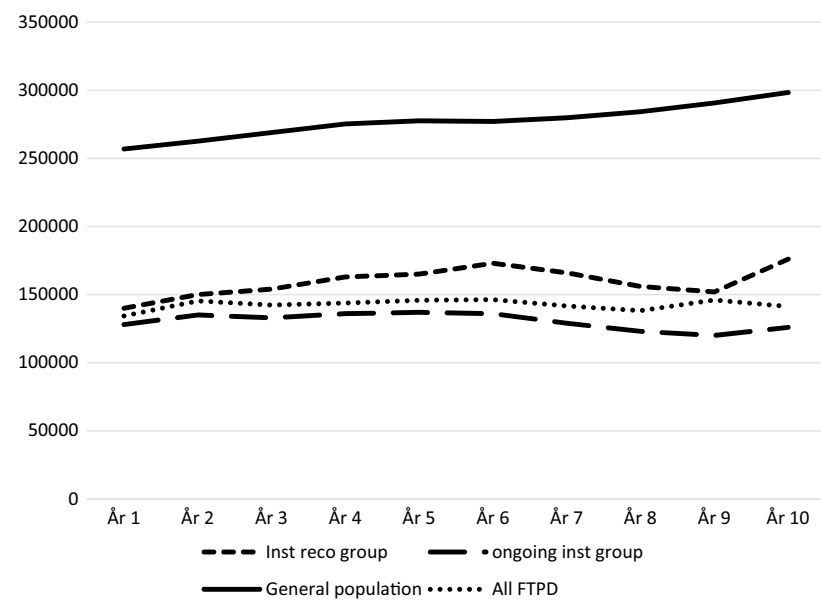

Fig. 1 Total incomes (salary and allowances) for the general population in Stockholm and all persons with a first-time psychosis diagnosis, and persons in the institutional recovery group and in the ongoing experiences of institutionalisation group (mean SEK/year). Age-standardised

population in Stockholm, a difference appears from the start. A gap of about 100,000 Swedish crowns (SEK) or about 10,000 euros was already present at year 1 (Fig. 1).

The difference between both groups is statistically significant from year 6 onwards.

As time goes by, the gap between the general population's income and the income for the FTPD group tends to grow. As the income for persons with a psychosis diagnosis remains stable over time, the income of the general population increases. At year 10, the difference is about 180,000 SEK (about 18,000 euros). As we have seen, persons with a first-time psychosis diagnosis are not a homogeneous group, but follow different recovery paths. Thus, even their financial development over the 10 years following their diagnosis shows different patterns.

When we separate the institutional recovery group from the recovery with institutionalisation group, some important differences appear. The first group's income increases by about 40,000 SEK/year (about 4000 euros).

Persons with an ongoing institutional contact see their income diminish by 2000 SEK/year (about 200 euros) during the same period. Thus, at year 10, this group shows a lower income both in absolute and in relative numbers than at the beginning of the follow-up period.

Even the group following an institutional recovery path loses ground on the economic field compared to the general population, whose income increases twice as much; 80,000 SEK/year (about 8000 euros).

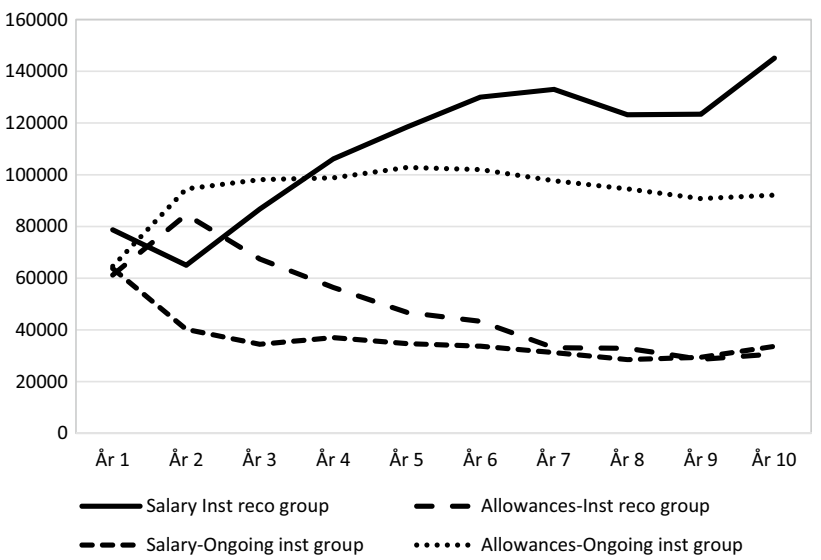

Fig. 2 Salary compared to the total allowances over 10 years for the institutional recovery group vs. the ongoing experiences of institutionalisation group (SEK/year)

\section{Sources of income according to recovery paths}

People's income can come from different sources. In welfare countries, one can expect that the social security system will provide some relief for persons in need of financial support due to illness and unemployment.

How are the different institutional recovery groups paths reflected when looking at their sources of income (Fig. 2)?

For both groups, the differences between salary, as well as allowances are statistically significant from year 3 onwards. Persons with an institutional recovery tended to return to the labour market and had the major part of their income as salary. Persons, who had ongoing experiences of institutionalisation during the last 5 years of the follow-up study, show a clear drop in their income based on salary already during year 1 . During the following 9 years, this level remains constant.

The reverse development can be noticed when regarding the economic support from the welfare state. The institutional recovered group received economic support primarily during year 1 as their income from salary decreased. However, as their presence on the labour market increased the welfare support started to decrease. For the ongoing experiences of institutionalisation group, their income from welfare support mirrored their reduced payroll rates.

\section{Sources of income}

The compensatory function of the welfare system was not total as we noticed a difference in the total income between the two groups; the incomes also came from different sources (Table 3).

We looked for five sources of income: salary, sick pension, financial social support, sickness benefit, and unemployment benefit. Salary, and sickness and unemployment 
Table 3 Proportion (\%) of persons in the institutional recovery group vs the ongoing experiences of institutionalisation group with income from different sources

\begin{tabular}{lrrrrr}
\hline Source of income & \multicolumn{2}{c}{ Inst. Recovery group } & & \multicolumn{2}{c}{ Ongoing inst group } \\
\cline { 2 - 3 } \cline { 6 - 6 } \cline { 5 - 6 } & Year 1 & Year 10 & & Year 1 & Year 10 \\
\hline Salary & 70 & 60 & & 53 & 27 \\
Disability pension & 8 & 21 & & 20 & 61 \\
Financial support from & 30 & 4 & & 41 & 26 \\
$\quad$ social services & & & & \\
Sickness benefit & 40 & 15 & & 30 & 16 \\
Unemployment benefit & 11 & 2 & 6 & 4 \\
\hline
\end{tabular}

benefit were connected to an actual or previous presence on the labour market. Disability pension meant that the person was not expected to return to the labour market. Social support could be obtained independently of the persons' connection to the labour market.

Regarding the persons in the institutional recovery group, we can notice a drop by $10 \%$, from 70 to $60 \%$, for those receiving a salary. During the 10 -year period, the percentage of persons, whose source of income was disability pension increases from eight to $21 \%$. The percentage of persons with all other forms of support decreases, social financial support, and sickness benefit near to null.

Regarding the ongoing experiences of institutionalisation group, we can see a decrease in the percentage of persons having a salary, near a halving, and a threefold increase of persons receiving disability pension from 20 to $61 \%$; indicating a move from the labour market. All the other forms of support tend to decrease with time, even if they remain at a higher level compared to the institutional recovery group. A quarter of the ongoing experiences of institutionalisation group receive financial social support.

The different forms of financial welfare support increased for both groups, as their presence on the labour market decreased at the time they received their FTPD. However, as persons in the institutional recovery group tended to return to the labour market, all forms of financial support decreased, except for disability pension. Disability pension was, on the other hand, the source of income for the majority of the persons in the ongoing experiences of institutionalisation group.

\section{Discussion}

There was a wage tendency that the group with ongoing experience of institutional contact to a higher degree was divorced, had no children at home, and had longer contact with psychiatric care-eventually indicating more SMHP compared to the institutional recovery group. Other background variables did not differ between the two service outcome groups.

In general, receiving a psychosis diagnosis tends to be connected to a lesser presence on the labour market and consequently to a fall in one's income level.

\section{Income and social welfare}

In Sweden, this drop is counteracted through the public social security system. However, most of those general insurances are connected to one's prior presence on the labour market. For persons that have not entered this market, the only possible source of public financial support is the social services. Confirming the findings of Falk et al. [28], the different forms of support developed by the welfare state seem to reduce, but not fully compensate for, the economic consequences of the illness, even for a person who has previously participated in the labour market.

Over the 10 years of the follow-up, we can notice how the gap between the income from persons with a first psychosis diagnosis and the general population increased by over $30 \%$. At the tenth year, the general population's income was twice the income of the follow-up group, thus, reaching the relative poverty level. SMHP seemed to cause relative poverty, even in welfare states. This might partly be due to an ongoing deterioration of the different social security systems, entailing a lower level of remuneration and/or a shorter time a person might be eligible have to receive payments. Even the criteria to get access to different types of remuneration have also made stricter [29].

\section{Recovery, work, and income}

Since persons with a first-time psychosis diagnosis follow different institutional recovery paths, we chose to compare two groups with opposite institutional recovery processes. The first group consisted of persons without any contact either with psychiatric or social services during the follow-up period's last five years (institutional recovery). The second group consisted of persons who had received institutional and community-based psychiatric and/or social care during the same period (ongoing experiences of institutionalisation).

Not surprisingly, the incomes for the two groups differed. The income of the first group was 50,000 SEK (about 5000 euros) a year (about 30\%) higher compared to the second group at year 10.

Even the sources of income differed between the groups. Three times more people from the second group had a disability pension, and five times more received financial social support. On the other hand, in the first group, nearly, 2.5 times more people had a salary compared with the group with ongoing experiences of institutionalisation. 
Institutional recovery was often connected to a return to the labour market, but not returning to the income level of the general population. Already, at year 1, when the persons in the follow-up received their FTPD, we noticed a gap of around 100000 SEK (about 10,000 euros), compared to the general population. This might, at least partly, be due to a period of illness prior to the diagnosis. Another possible explanation could be that, generally, persons with SMHP are more frequent in lower social status groups [18].

The persistence and even widening of an income gap, even after a return to the labour market might be explained in different ways. Probably, not all persons with an institutional recovery worked full time and they might not have been able to get well-paid jobs. As working is often connected to expenses for travelling, food, and clothes, the result of working might be a deteriorated financial situation $[8,30]$.

Work on the regular labour market is often proposed as the main road out of poverty for persons with SMHP [31, 32]. Different initiatives have been taken to sustain this option, ranging from a reduction of taxes to "stimulate" people outside the labour market to start working, to the introduction of evidence-based interventions such as Individual Placement and Support to help persons with SMHP in their efforts to find work and maintain it [33].

Part-time, low-paid work with low-level expectations and no control over the work conditions might lead to mental health risks both for persons with or without mental health problems. The risk for ill health for people working and living under such conditions might be higher than for persons on unemployment benefits [8, 34].

Accepting the definition of relative poverty as below $60 \%$ of the general population's median income, the median income of the follow-up participants was below this level at the time they received their psychosis diagnosis, compared to the median income of the inhabitants in the Stockholm region. Ten years later, they were clearly below that level.

Placing our findings in a contemporary context, we saw that, in the middle of the 1990s, the economic situation of persons with SMHP was inferior compared to the general population in Sweden and even compared to persons with other forms of disabilities. This knowledge led to a focus on normalisation of the living conditions of persons with SMHP in connection to the closing of mental hospitals. Despite this, the data we have presented show growing differences between persons with SMHP and the general population.

\section{Poverty and recovery}

The continuous financial strain connected to SMHP poses some core problems, both to our understanding of SMHP, "illnesses", and "disorders" and to the elaboration of adequate interventions to ease the pain connected to them.
There is a growing body of knowledge about the confusion existing between, on one hand, the behaviours and suffering that are often considered to be symptoms of "severe mental illness", and on the other hand, what could be considered as fully understandable and normal reactions to oppressive living conditions and experiences [35].

Mood \& Jonsson [36] studied how a period of relative poverty affected people from the general population and showed a reduction of their social networks and activities. This type of reduction is often interpreted as a tendency towards passivity and isolation, which are considered symptoms of mental illness when it comes to people diagnosed with SMHP [37]. On the other hand, the persons themselves connected their isolation and "passivity" to the living conditions. Poverty made it difficult to go to the usual places for social intercourse, such as coffee houses and restaurants, but also made it hard to visit friends and relatives and to invite them to one's home to maintain a reciprocal situation. Consequences of prolonged poverty could be a deteriorated physical health status, old, worn out clothes and other factors preventing one taking part in social situations [20, 21, 38].

Studies of supported socialisation, where persons with SMHP received a certain amount of extra money, show that their social networks tended to increase. Their quality of life and sense of self improved. Symptoms such as depression and anxiety decreased [22, 23, 25, 39]. In addition, the users themselves have pointed to financial strain as one of their main problems $[40,41]$.

In this context, it is noteworthy that there seems to be a serious lack of interest, except in policy documents, both from most of the professional mental health community and policy makers, in directly improving the financial situation for persons with SMHP [42].

In an editorial in World Psychiatry, Priebe [43] declared that there was no need for more research about prevention of mental illness. He claimed that we already knew enough and pointed to some interventions on a structural level to prevent mental ill health in the community. One of the changes he put forward was a decrease of income inequality. The results from several studies, the knowledge-based user claims are present. Is it time for changes?

Acknowledgements This work was supported by The Swedish Research Council for Health, Working Life and Welfare, grant nr: 2014-0117.

\section{Compliance with ethical standards}

Ethical approval The study was approved by The Regional Ethical Review Board in Stockholm in 2005 (ref. 2005/2: 1) in 2009 (ref. 2009/806-2) and in 2015 (ref 2015/1155-32).

Conflict of interest The authors declare that they have no conflicts of interest. 
OpenAccess This article is distributed under the terms of the Creative Commons Attribution 4.0 International License (http://creativeco mmons.org/licenses/by/4.0/), which permits unrestricted use, distribution, and reproduction in any medium, provided you give appropriate credit to the original author(s) and the source, provide a link to the Creative Commons license, and indicate if changes were made.

\section{References}

1. Goffman E (1961) Asylums - essays on the social situation of mental patients and other inmates. Doubleday \& Co., New York

2. Nirje B (1985) The basis and logic of the normalization principle. Aust N Z J Dev Disabil 11:65-68

3. Konrad N (2002) Prisons as new asylums. Curr Opin Psychiatry 15:583-587

4. Priebe S, Turner T (2003) Reinstitutionalisation in mental health care. BMJ 326:175-176

5. Priebe S, Badesconyi A, Fioritti A, Hansson L, Kilian R, TorresGonzales F, Wiersma D (2005) Reinstitutionalisation in mental health care: comparisons of data on service provision from six European countries. BMJ 330:123-126

6. Dear M, Wolch J (1987) Landscape of despair. From deinstitutionalization to homelessness. Polity Press, Cambridge

7. Knowles C (2000) Burger King, Dunkin Donuts and community health care. Health Place 6:213-224

8. Priebe S, Warner R, Hubschmid T, Eclde I (1998) Employment, attitudes toward work, and quality of life among people with schizophrenia in three countries. Schizophr Bull 24:469-477

9. Harding C (2005) Changes in schizophrenia across time. Paradoxes, patterns and predictors. In: Davidson L, Harding C, Spaniol L (eds) Recovery from severe mental illnesses: Research evidence and implications for practice. Center for Psychiatric Rehabilitation, Boston University, Boston, pp 27-48

10. Hegelstad WT, Larsen TK, Auestad B et al (2012) Long-term follow-up of the TIPS early detection in psychosis study: effects on 10-year outcome. Am J Psychiatry 169:374-380. https://doi. org/10.1176/appi.ajp.2011.11030459

11. Bellack AS (2006) Scientific and consumer models of recovery in schizophrenia: Concordance, contrast and implications. Schizophr Bull 32:432-442

12. Liberman RP, Kopelowicz A (2005) Recovery from Schizophrenia: A concept in search of research. Psychiatric Services 56:735-742

13. Bergmark M, Bejerholm U, Markström U (2017) Policy changes in community mental health: interventions and strategies used in Sweden over 20 years. Social Policy Adm 51:95-113

14. SOU (1992) Psychiatry and its patients-living conditions, the content and change of care. SOU 37

15. Socialstyrelsen (The National Board for Health and Welfare) (1999) Välfärd och valfrihet. Slutrapport från utvärderingen av 1995 års psykiatrireform (Welfare and freedom of choice. Report from the evaluation of the 1995-year's psychiatric reform). Socialstyrelsen, Stockholm, p 1

16. Socialstyrelsen (The National Board for Health and Welfare) (2010) Alltjämt ojämlikt! Levnadsförhållanden för vissa personer med funktionsnedsättningar (Still unequals! Living conditions for some people with disabilities). Socialstyrelsen, Stockholm

17. Socialstyrelsen (The National Board for Health and Welfare) (2006) Handikappomsorg. Lägesrapporter (Disability care. Progress reports). Socialstyrelsen, Stockholm

18. Eaton WW (2001) The sociology of mental disorders, 3rd edn. Praeger Publishers, Westport
19. Read J (2010) Can poverty drive you mad? 'Schizophrenia', socioeconomic status and the case for primary prevention. N Z J Psychol 39:7-19

20. Ware NC, Goldfinger SM (1997) Poverty and rehabilitation in severe psychiatric disorders. Psychiatr Rehabil J 21:3-7

21. Wilton RD (2003) Poverty and mental health: A qualitative study of residential care facility tenants. Community Ment Health J 39:139-156

22. Topor A, Ljungqvist I, Strandberg E-L (2016) The cost of friendship: severe mental illness, poverty and social isolation. Psychosis 8:336-345. https://doi.org/10.1080/17522439.2016.1167947

23. Davidson L, Shahar G, Stayner DA, Chinman MJ, Rakfeldt J, Kraemer Tebes J (2004) Supported socialization for people with psychiatric disabilities: lessons from a randomized controlled trial. J Commun Psychol 32:453-477

24. Mattsson M, Topor A, Cullberg J, Forsell Y (2008) Association between financial strain, social network and five-year recovery from first episode psychosis. Social Psychiatry Psychiatric Epidemiology 43:947-952

25. Topor A, Ljungqvist I (2017) Money, social relationships and the sense of self: the consequences of an improved financial situation for persons suffering from serious mental illness. Community Ment Health J 53:823-831

26. Topor A, Mattsson M, Denhov A, Bülow P, Holmqvist S, Davidson L (2011) The Stockholm follow-up study of users diagnosed with psychosis (SUPP): methodology, patient cohort and services. Psychosis 4:246-257

27. Topor A, Stefansson C-G, Denhov A, Bülow P, Andersson $G$ (2018) Institutional recovery. A ten-year follow-up study of persons after their first psychosis diagnosis; a critical reflexive approach. Psychosis. https://doi.org/10.1080/17522 439.2018.1511746

28. Falk J, Burström B, Dalman C, Jörgensen L, Bruce D, Nylén L (2016) Employment and income among first-time cases diagnosed with non-affective psychosis in Stockholm, Sweden: a followup study 2004/2005-2010. Soc Psychiatry Psychiatr Epidemiol $51: 259-267$

29. Nelson K (2013) Social assistance and EU poverty thresholds 1990-2008. Are European Welfare systems providing just and fair protection against low income? Eur Sociol Rev 29:386-401

30. Beresford P (1996) Poverty and disabled people: Challenging dominant debates and policies. Disabil Soc 11:553-567

31. Borg M, Veseth M, Binder P-E, Topor A (2013) The role of work in recovery from bipolar disorders. Qual Social Work 12:323-339

32. Warner R (2009) Recovery from schizophrenia and the recovery model. Curr Opin Psychiatry 22:374-380

33. Bejerholm U, Areberg C, Hofgren C, Sandlund M, Rinaldi M (2015) Individual placement and support in Sweden-a randomized controlled trial. Nord J Psychiatry 69:57-66

34. Starrin B, Janson S (2006) Unemployment, secure employment and insecure employment: differences in self-reported ill health. In: Kieselbach T, Winefield AH, Boyd C, Anderson S (eds) Unemployment and health. International and interdisciplinary perspectives. Australian Academic Press, Sydney

35. Mills C (2015) The psychiatrization of poverty: rethinking the mental health-poverty nexus. Soc Pers Psychol Compass 9:213-222

36. Mood C, Jonsson JO (2015) The social consequences of poverty: an empirical test on longitudinal data. Social Indic Res 127:633652. https://doi.org/10.1007/s11205-015-0983-9

37. Seeman MV (2017) Solitude and schizophrenia. Psychosis 9:176183. https://doi.org/10.1080/17522439.2016.1264992

38. Author et al. (2014)

39. Sheridan A, Drennan J, Coughlan B et al (2015) Improving social functioning and reducing social isolation and loneliness among people with enduring mental illness: report of a randomized 
controlled trial of supported socialization. Int J Soc Psychiatry 61:241-250. https://doi.org/10.1177/0020764014540150

40. Bengtsson-Tops A, Hansson L (1999) Subjective quality of life in schizophrenic patients living in the community. Relationship to clinical and social characteristics. Eur Psychiatry 14:256-263

41. Onken SJ, Dumont JM, Ridgway P, Doman DH (2002) Mental health recovery: what helps and what hinders? National, Technical Assistance Center for Mental Health Planning, Alexandria
42. Lund C (2012) Poverty and mental health: a review of practice and policies. Neuropsychiatry $2: 1-7$

43. Priebe $S$ (2015) The political mission of psychiatry, World Psychiatry, 14: 1 